\title{
Retinoids Augment Thiazolidinedione PPAR $\gamma$ Activation in Oral Cancer Cells
}

\author{
RAUL ROSAS ${ }^{1}$, SETH BURYSKA ${ }^{2}$, ROBERT SILVER ${ }^{3}$, BEVERLY WUERTZ ${ }^{2}$ and FRANK ONDREY ${ }^{2}$ \\ ${ }^{1}$ Ear, Nose, \& Throat Surgery, Essentia Health, Duluth, MN, U.S.A.; \\ ${ }^{2}$ Department of Otolaryngology-Head and Neck Surgery, University of Minnesota, Minneapolis, MN, U.S.A.; \\ ${ }^{3}$ Ear, Nose \& Throat Specialty Care, Minneapolis, MN, U.S.A.
}

\begin{abstract}
Background/Aim: Head and neck squamous cell carcinoma affects nearly 500,000 people annually. Augmenting PPAR $\gamma$ functional activation is linked with multiple anticarcinogenic processes in aerodigestive cell lines and animal models. PPAR $/ R X R \alpha$ heterodimers may be key partners in this activation. Materials and Methods: CA 9-22 and NA cell lines were treated with the PPAR $\gamma$ agonist ciglitazone and/or the RXR a agonist 9-cis-retinoic acid. PPAR $\gamma$ functional activation, cellular proliferation, apoptosis activity, and phenotype were subsequently analyzed. Results: Ciglitazone and 9-cis-retinoic acid independently activated PPAR $\gamma$ and down-regulated the carcinogenic phenotype in vitro. Combination treatment significantly augmented these effects, further decreasing proliferation $(p<0.0001)$, and increasing PPAR $\gamma$ functional activation $(p<0.0001)$, apoptosis $(p<0.05)$, and adipocyte differentiation markers $(p<0.0001)$. Conclusion: The efficacy of the combination of ciglitazone and 9-cis-retinoic acid afforded lowering treatment concentrations while maintaining desired therapeutic outcomes, optimistically supporting the feasibility and practicality of this novel treatment option.
\end{abstract}

Head and neck squamous cell carcinoma (HNSCC) affects nearly 500,000 individuals worldwide every year (1). The $20-50 \%$ survival rate of stage III and IV disease has remained stagnant over multiple decades despite advances in research and multi-modality treatment protocols $(1,2)$. This illuminates the imperative need for novel treatment options. Nuclear hormone receptor targeting has revealed its therapeutic

This article is freely accessible online.

Correspondence to: Beverly Wuertz, Department of OtolaryngologyHead and Neck Surgery, University of Minnesota, 420 Delaware St SE, MMC 396, Minneapolis, MN 55455, U.S.A. Tel: +1 6126253090, Fax: +1 6126269871, e-mail: knier003@umn.edu

Key Words: PPAR $\gamma$, ciglitazone, thiazolidinedione, 9-cis-retinoic acid, retinoids, head and neck squamous carcinoma. potential in a variety of cancers (3). A class of nuclear receptors, peroxisome proliferator-activated receptors (PPAR), were originally recognized for their role in regulating lipid and glucose metabolism $(4,5)$. These are therapeutic targets of interest with respect to HNSCC. An isoform of the PPAR family, PPAR $\gamma$, is an intriguing target; initially described as an adipocyte differentiation transcription factor $(6,7)$. Cancer cells are characterized by the lack of differentiation, thus, attempting to induce differentiation may be exploitable as a treatment strategy. Differentiation therapy has previously demonstrated value as a novel treatment strategy for non-small cell lung cancer $(8,9)$, as well as for acute promyelocytic leukemia $(10$, 11). Research has shown that PPAR $\gamma$ can form a heterodimer with retinoic $\mathrm{X}$ receptor alpha $(\mathrm{RXR} \alpha)$ and transcriptionally activate down-stream genes $(5,7)$. In lipid biology, this process has directed malignant precursor cells into non-malignant adipocytes (12). Once activated, it has been postulated that the PPAR $\gamma / \operatorname{RXR} \alpha$ heterodimer transcription factor may regulate multiple pathways with the following downstream anticarcinogenic effects: decreased proliferation, decreased angiogenesis, and increased apoptosis (13). Research has demonstrated that cellular dysfunction involving this pathway, adversely stunting PPAR $\gamma$ expression, is linked to multiple cancerous etiologies including colorectal carcinomas (14) and poorly differentiated adenocarcinoma $(5,15)$.

Research has also demonstrated that thiazolidinedione (TZD) drugs such as pioglitazone, rosiglitazone, troglitazone, and ciglitazone, conventionally used to treat type II diabetes mellitus, can functionally activate $\operatorname{PPAR} \gamma$ pathways, inducing the aforementioned anti-carcinogenic effects (8). Epidemiological analysis of 85,000 diabetic patients demonstrated that those prescribed thiazolidinedione drugs had a $33 \%$ decreased prevalence of aerodigestive lung cancer, another tumor type associated with tobacco use, when compared to a control population (16). Previous clinical trials assessing thiazolidinedione treatments for liposarcoma (17), breast (18), and prostate cancer (19) are also encompassed in this developing field. There is multidisciplinary evidence for attempting to exploit this pathway for cancer treatment and prevention. 
With respect to head and neck squamous malignancies, previous studies have demonstrated that PPAR $\gamma$ expression was suppressed in comparison to normal squamous lining tissues which were not cancerous, accentuating the possibility that induction of PPAR $\gamma$ might be a treatment strategy to restore cancer cell homeostasis to a more normal phenotype $(5,7,20)$. Furthermore, there was a dose dependent decrease in cell proliferation and clonogenicity of oral cancer cells in response to several classes of PPAR agonists (20).

Interventions with similar PPAR $\gamma$ agonists have documented synergistic effects when combined with conventional chemotherapeutic agents $(21,22)$. As $\operatorname{RXR} \alpha$ is a principal component of the heterodimer with PPAR $\gamma$ (13), a retinoic acid could augment PPAR $\gamma$ activity when combined with another transcription factor agonist such as a thiazolidinedione. However, the historic implementations of retinoic acids for differentiation therapy have been limited due to the toxic effects of retinoids and the reversal of effects upon cessation of treatment $(23,24)$. The aims of this study were to examine the activity of the RXR agonist 9-cis-retinoic acid (9cRA), as it is FDA approved and has demonstrated to be better tolerated in clinical populations (25), and the preclinical thiazolidinedione ciglitazone (CTZ) in an attempt to examine the feasibility of activating both RXR $\alpha$ and PPAR $\gamma$ as a combination strategy for head and neck cancer treatment or prevention.

\section{Materials and Methods}

Cell culture. Mycoplasma free CA 9-22 and NA aerodigestive cell lines were cultured at $37^{\circ} \mathrm{C}, 5 \% \mathrm{CO}_{2}$ as adherent monolayer cultures in RPMI 1640 Media supplemented with 2mM Glutamine, 10\% heat-inactivated FBS (ThermoFisher, Grand Island, NY, USA) 50 $\mathrm{U} / \mathrm{ml}$ Penicillin, and $50 \mu \mathrm{g} / \mathrm{ml}$ streptomycin (26). Log-phase cells were routinely subcultured weekly via trypsinization.

Reagents. Ciglitazone (CTZ) was purchased from Biomol (Plymouth Meeting, PA, USA), 9-cis-retinoic acid (9cRA) from Millipore-Sigma (St. Louis, MO, USA).

Luciferase reporter gene assays. PPAR $\gamma$ ligand-mediated transcriptional activation was analyzed via luciferase reporter gene assay performed as we have previously published (20). Human oral squamous cell lines CA 9-22 and NA were transiently infected with thymidine kinase luciferase-containing reporter plasmid for the PPAR $\gamma$-dependent gene acyl-CoA oxidase TK-PPREx3 (kindly gifted by Ron Evans). This contains TK-PPREx3-LUC [PPRE x 3(5';GTCGACAGGGGACCAGGACAAAGGTCACGTTCGGGAGTCG AC), three copies], and when PPAR $\gamma$ binds to these PPAR response elements, the reporter construct produces luciferase. Cells at $60-80 \%$ confluence were co-transfected with $2 \mu \mathrm{g} / \mathrm{ml}$ TK-PPREx3-Luc reporter plasmid and $0.4 \mu \mathrm{g} / \mathrm{ml} \beta$-Galactosidase containing DNA reporter via cationic lipid transfection (Lipofectamine at $10 \mu \mathrm{g} / \mathrm{ml}$ in Opti-MEM (ThermoFisher) for $4 \mathrm{~h}$. Cell lines were then treated for $24 \mathrm{~h}$ with CTZ and/or 9cRA. Relative luciferase activity (RLU) was assayed with the Dual-Light reporter gene assay system (ThermoFisher) using the
Tropix model TR717 dual injection plate luminometer (Berthold Technologies, Oak Ridge, TN, USA) and luciferase was normalized to $\beta \mathrm{Gal}$. Three assays were performed in triplicate wells for a total of nine replicates per data point.

MTT cell proliferation assay. Cell proliferation was determined using the MTT reaction assay (Boehringer Mannheim, Indianapolis, IN, USA). CA 9-22 and NA cells at a density of $7.5 \times 10^{4}$ cells/well were seeded in 96-well plates (Corning, Corning, NY, USA). Cell lines were treated with CTZ and/or 9cRA in serum free media on day 0 . On day $0,1,3$ and 5, $0.5 \mathrm{mg} / \mathrm{ml}$ 3-(4,5-Dimethyl-2-thiazolyl)-2,5diphenyl-2H-tetrazolium bromide were added to the culture media and incubated at $37^{\circ} \mathrm{C}$ for $4 \mathrm{~h}$. Mitochondrial dehydrogenases of live cells convert MTT to a water insoluble purple formazan, which we then solubilized in isopropyl alcohol/DMSO. The absorbance was analyzed at $560 \mathrm{~nm}$ on a Tecan model 530 plate spectrophotometer using Tecan software (Tecan, Morrisville, NC, USA). Six replicates of each test group were assayed.

Probe preparation. The RXR (DR-1) probe and the mutant oligonucleotide containing two "GT" $\rightarrow$ "CA" substitutions in the RXR binding motif, was obtained commercially and contained the following sequence: 5';-AGC TTC AGG TCA GAG GTC AGA GAG CT-3'; (sc-2547, Santa Cruz Biotech, Inc., Dallas, TX, USA), 5';-AGC TTC AGC ACA GAG CAC AGA GAG CT-3'; (sc-2548, Santa Cruz Biotech, Inc.), respectively. The Cyp4A1 probe was manufactured by GibcoBRL, part of ThermoFisher, as a sense and anti-sense oligonucleotide. The Cyp4A1 probe contained the published Cyp4A1sequence, 5';-TGA AAC TAG GGT AAA GTT CA-3'; Cyp4A1 DNA strands were annealed by heating in annealing buffer $(0.1 \mathrm{mM}$ Tris- $\mathrm{HCl}, 1.0 \mathrm{M} \mathrm{NaCl}, 1 \mathrm{x}$ React2 (GibcoBRL/ThermoFisher), $300 \mathrm{pM}$ oligonucleotide) to $60^{\circ} \mathrm{C}$, and then cooled to room temperature. End labeling with T4 polynucleotide kinase (Promega, Madison, WI, USA) and $\gamma$-32-ATP $(6000 \mathrm{Ci} / \mathrm{mmol}$, Amersham, Arlington Heights, IL, USA). Double stranded DNA oligonucleotide probes for OCT-1 were obtained commercially (Promega).

EMSA binding reactions and shift assays. Electromobility shift assay (EMSA) binding reactions consisted of $5 \mu \mathrm{g}$ of nuclear extract protein and performed identical to previous studies (8). Gels were imaged with phosphor imaging with a Packard Cyclone Phosphorimager utilizing multipurpose imaging screens and analyzed by Optiquant software (Packard Technologies, Downers Grove, IL, USA). Each EMSA reaction was performed with at least two separate nuclear extract preparations. Supershift reactions utilized $1 \mu \mathrm{g}$ of antibody for RXR $\alpha$ (sc-553, Santa Cruz) or PPAR $\gamma$ (sc-7273, Santa Cruz) added $12 \mathrm{~h}$ prior to binding reactions with the labeled probes. All reactions carried out at $4{ }^{\circ} \mathrm{C}$ and densitometry analysis was performed with Optiquant software.

Caspase 3/7 assay. Apoptosis was analyzed by monitoring caspase $3 / 7$ activity. NA and CA 9-22 cells were plated at $10 \times 10^{3}$ cells/well density in opaque clear bottom 96 well plates. Treatments, alone and in combination, were added the following day. After 24 hours of treatment the caspase $3 / 7$ activity was assayed via Caspase-Glo ${ }^{\circledR}$ 3/7 assay (Promega), a luminescent assay which provides a signal proportional to caspase $3 / 7$ activity. The single Caspase-Glo ${ }^{\circledR} 3 / 7$ reagent lyses the cells and caspase cleavage of the substrate results in free aminoluciferin, which is consumed by the luciferase, creating a glow-luminescent signal proportional to caspase-3/7 activity. 
A

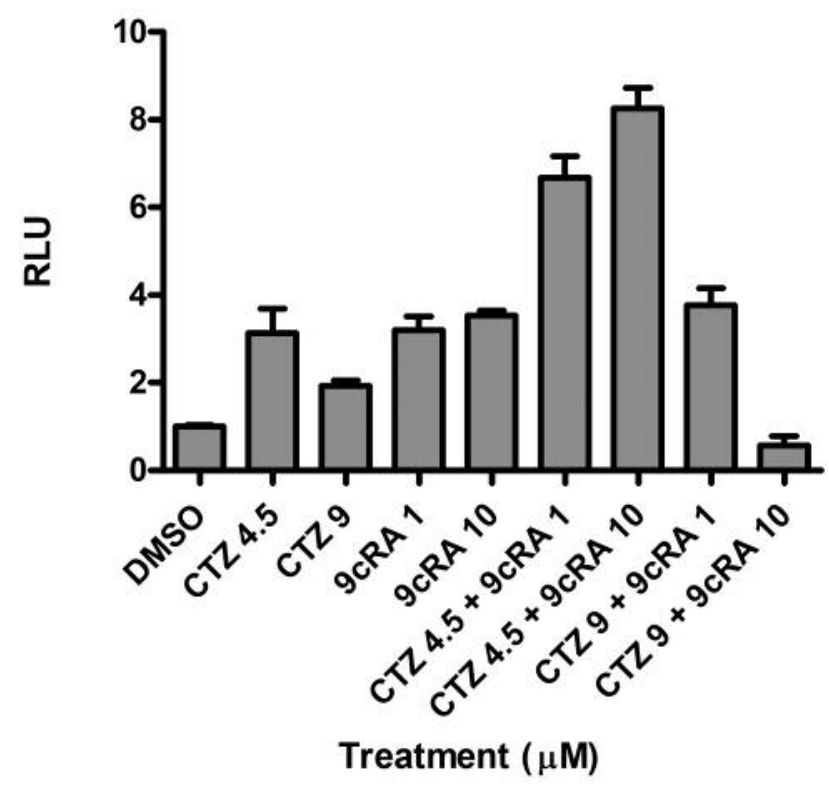

B

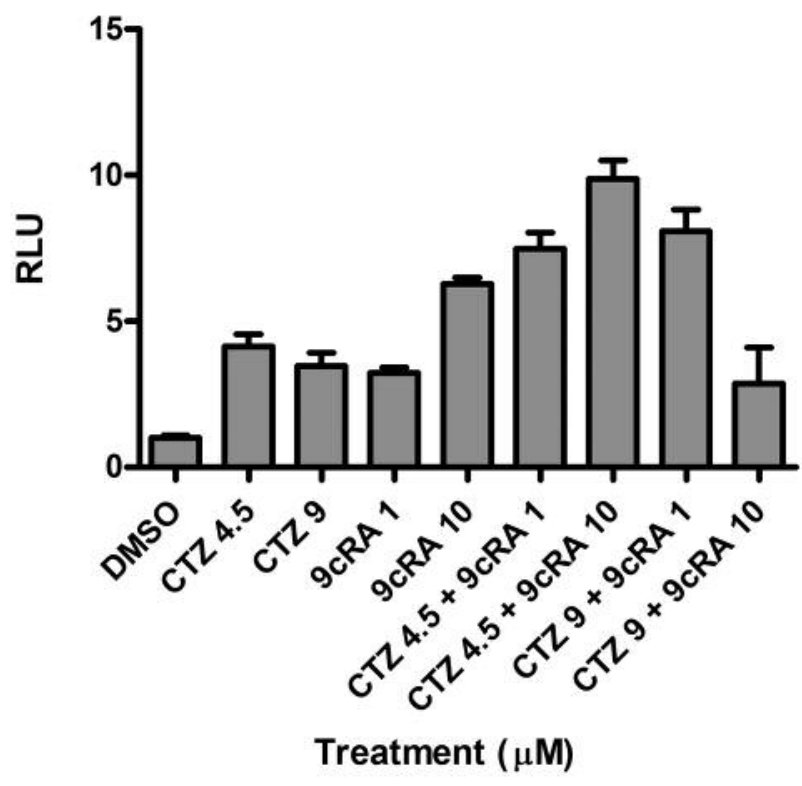

Figure 1. Reporter gene activity in NA and CA 9-22 cell lines treated with ciglitazone (CTZ) and/or 9-cis-retinoic acid (9cRA) for 24 h. RLU (yaxis) is representative of relative luciferase activity (RLU), normalized to $\beta$ Gal. Each column is the average of nine data points. Graph A represents the NA cell line. Graph B represents the CA 9-22 cell line. One-way ANOVAs employed a Tukey post-test, and t-tests were unpaired. Treatment with low-dose CTZ $(4.5 \mu M)$ or 9cRA $(1 \mu M)$ increased RLU by $>300 \%$ in both cell lines ( $t$-test: p $<0.0001)$. Combination treatment of low-dosages further augmented RLU activity by approximately two-fold when compared to individual treatments, and by a $>500 \%$ increase when compared to controls for both cell lines ( $t$-test: $p<0.0001)$. Difference between control, individual, and combination treatments at these concentrations were significant for CA 9-22 cells $[F(3,32)=351.7, p<0.0001)]$ and $N A$ cells $[F(3,29)=232.2, p<0.0001)]$. These experiments were repeated multiple times with similar results.

Oil red $O$. CA 9-22 cells were cultured in 12-well plates at $10 \times 10^{4}$ cells/well in complete RPMI media and allowed to attach overnight. Cells were allowed to grow to 50-60\% confluence and experimental groups were then treated with CTZ alone, CTZ plus 9cRA, 9cRA alone, or vehicle solvent, DMSO, for 72-96 h. Cell cultures were incubated at $37^{\circ} \mathrm{C}$ in $5 \% \mathrm{CO}_{2}$. Oil red $\mathrm{O}$ solution $(0.2 \%$ in isopropyl alcohol) was then applied for 15 minutes; cells were then rinsed twice with 50\% isopropyl alcohol and finally with deionized water. Digital microphotographs were obtained using a SPOT Junior camera with SPOT Basic imaging software (SPOT Imaging, Sterling Heights, MI, USA). During analysis, all images were converted to 16-bit files in ImageJ software and standard background subtraction was applied. Standardized threshold techniques were used in order to identify vacuoles. Images were converted to binary masks and subsequently analyzed. The results were split into quadrants and independently assessed for vacuoles per cell. A minimum of 10 cells were included in the analyses of each test group.

Statistical analysis. Data are presented as mean \pm standard deviation. Graph Pad Prism 8 was utilized for all statistical analyses. Unpaired two-tailed $t$-test was used when comparing two treatment groups. ANOVA and other tests with post corrections are listed in the results section and figure legends as indicated. $p$-Values $<0.05$ were considered significant.

\section{Results}

Luciferase reporter gene assays. We first examined functional activation of PPAR $\gamma$ by 9-cis-retinoic acid (9cRA) and/or ciglitazone (CTZ) in NA and CA 9-22 cell lines, as judged by luciferase reporter gene activity (expressed as RLU, relative luciferase units). Data were analyzed for statistical significance via one-way ANOVA analyses with Tukey post-test and unpaired student $t$-tests. With respect to NA cell lines, independent treatments with both low-dose CTZ $(4.5 \mu \mathrm{M})$ or 9cRA $(1 \mu \mathrm{M})$ significantly increased PPAR $\gamma$ functional activity by $>200 \%$ ( $t$-test: $p<0.0001)$. One-way ANOVA analysis of 9cRA treatments also showed significant dose-dependent differences between control, low $(1 \mu \mathrm{M})$, and high-dose $(10 \mu \mathrm{M})$ treatments $[\mathrm{F}(2,21)=178.1$, $p<0.0001)$ ] (Figure 1A).

Combination 4.5 $\mu \mathrm{M} \mathrm{CTZ}$ and $1 \mu \mathrm{M}$ 9cRA treatment augmented PPAR $\gamma$ DNA binding activation, resulting in an average of $>500 \%$ increase when compared to control, and an average 2-fold increase compared to treatment only with $4.5 \mu \mathrm{M}$ CTZ ( $t$-test: $p<0.0001)$. One-way ANOVA showed significant dose-dependent differences between treatment 
groups $4.5 \mu \mathrm{M} \mathrm{CTZ}, 4.5 \mu \mathrm{M} \mathrm{CTZ}+1 \mu \mathrm{M}$ 9cRA, $4.5 \mu \mathrm{M}$ $\mathrm{CTZ}+10 \mu \mathrm{M}$ 9cRA, and control $[\mathrm{F}(3,29)=232.2$, $p<0.0001)]$. Combination treatment with $9 \mu \mathrm{M} \mathrm{CTZ}$ and 1 $\mu \mathrm{M}$ 9cRA also significantly increased PPAR $\gamma$ activation in comparison to treatment only with $9 \mu \mathrm{M} \mathrm{CTZ} \mathrm{(} t$-test: $p<0.0001$ ) (Figure 1A). These data demonstrate that both 9cRA and CTZ can functionally activate PPAR $\gamma$ individually, and the addition of 9cRA to CTZ increases the activation over a given concentration of CTZ alone.

Drug effects on CA 9-22 cells were similar to those in NA cells. Individual treatments with low-dose of CTZ or 9cRA significantly increased PPAR $\gamma$ DNA binding activity by an average of $>300 \%$ and $>200 \%$ increases, respectively ( $t$-test: $p<0.0001)$. One-way ANOVA analysis of the 9cRA effects confirmed statistically significant dose-dependent differences between vehicle control, low, and high-dose treatment conditions $[\mathrm{F}(2,24)=1,231, p<0.0001)]$ (Figure 1B). For both CA 9-22 and NA cells, $9 \mu \mathrm{M} \mathrm{CTZ} \mathrm{in} \mathrm{combination} \mathrm{with}$ 9cRA is associated with marked increased toxicity and cell death, as will be demonstrated in proliferation assays, indicating that lowered luciferase activity is associated with attenuated cellular activity.

Combination of $4.5 \mu \mathrm{M} \mathrm{CTZ}$ and $1 \mu \mathrm{M}$ 9cRA treatment significantly increased PPAR $\gamma$ activity by an average of $>80 \%$ compared to individual $4.5 \mu \mathrm{M} \mathrm{CTZ}$ treatment and $>600 \%$ when compared to control ( $t$-test: $p<0.0001)$. One-way ANOVA confirmed a statistically significant difference between vehicle control, $4.5 \mu \mathrm{M} \mathrm{CTZ}$, and 4.5 $\mu \mathrm{M} \mathrm{CTZ} \mathrm{combined} \mathrm{with} \mathrm{low} \mathrm{and}$ high-dose 9cRA $[\mathrm{F}(3,32)=351.7, p<0.0001)]$ (Figure 1B). Nine $\mu \mathrm{M}$ CTZ increased the rate of PPAR $\gamma$ transcription by $>200 \%$ when compared to control ( $t$-test: $p<0.0001)$. DNA binding activity again was augmented by adding $1 \mu \mathrm{M} 9 \mathrm{cRA}$ to $9 \mu \mathrm{M}$ CTZ treatment ( $t$-test: $p<0.001)$. One-way ANOVA analysis of these two experimental conditions in comparison to control indicated statistically significant differences $[F(2,24)=268.2$, $p<0.0001)$ ] (Figure 1B). Similar findings in our two oral cancer cell lines demonstrated that retinoids, in addition to thiazolidinediones, augmented PPAR $\gamma$ functional activation in oral cancer in vitro.

EMSA binding reactions and shift assays. To confirm the DNA binding reporter gene experiments, nuclear extracts were used for the identification of PPAR $\gamma$ heterodimer binding partners in CA 9-22 cells treated with 9cRA, or 9cRA with ciglitazone. In control cells, we found PPAR $\gamma$ heterodimer binding partners bind to a PPAR $\gamma$ consensus sequence at baseline (Figure 2, lane 2). Next, when cells were incubated with PPAR $\gamma, \operatorname{RXR} \alpha, \operatorname{RXR} \beta$ or RXR $\gamma$ antibodies, $\operatorname{PPAR} \gamma$ antibody supershifted the binding complex (Figure 2, lane 5), and a band corresponding to $\mathrm{RXR} \alpha$ nuclear protein was found in this complex as well (Figure 2, lane 3). When cells were also treated with 9cRA, we found intensification of the PPAR $\gamma$ shift complex (Figure 2, lane 6). We also found

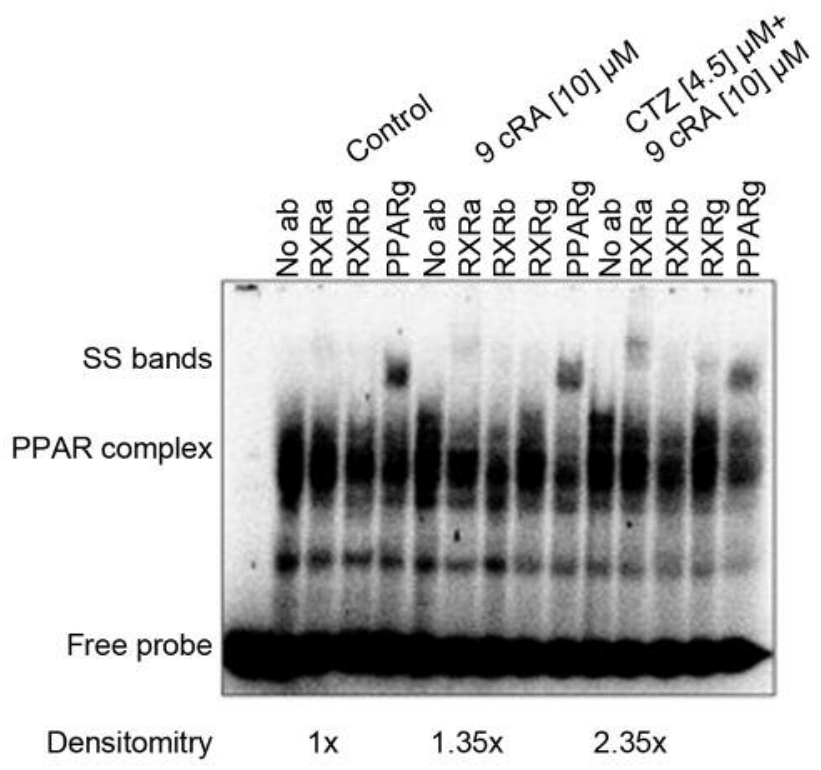

Figure 2. PPAR $\gamma$ and RXR EMSA supershift analysis of CA 9-22 cells after ciglitazone and 9-cis-retinoic acid treatment. Lane 1 is the control containing only the free probe. Lane 2 (no ab lane) demonstrates that $P P A R \gamma$ and $R X R \alpha$ bind to PPAR $\gamma$ consensus sequence at baseline. $R X R \alpha$ (Lane 3), RXR $\beta$ (Lane 4), and PPAR $\gamma$ (Lane 5) antibodies were preincubated with cells. RXR $\gamma$ was not used in the control due to lack of available space on the gel. Antibody pre-incubation treatments were performed, including $R X R \gamma$ (which is not shown on the gel), on cells treated with $10 \mu M$ 9cRA (Lanes 6-10) as well as $4.5 \mu M C T Z+10 \mu M 9 c R A$ treatment (Lanes 11-15). The PPAR complex is representative of the RXR $\alpha$ $P P A R \gamma$ heterodimer formation. SS bands are representative of supershift bands where an antibody is bound to the PPAR $\gamma-R X R \alpha$ heterodimer. There was a PPAR $\gamma$ supershift for all treatment conditions (Lanes 5,10,15). A faint supershift band is found in RXRa antibody treatments (Lanes 3,7,12). There is a faint supershift band in Lane 14 associated with RXRY antibodies. PPAR complex formation in the control was standardized to the value of 1 . Treatment with $10 \mu M 9 c R A$ resulted in a $35 \%$ increase in intensification of the PPAR $\gamma$ shift complex (Lane 6) while the combination treatment resulted in a $135 \%$ increase in comparison to control (Lane 11). This experiment was repeated with similar results.

increasing density of the RXR $\alpha$ band (Figure 2, lane 7) as well as a PPAR $\gamma$ supershift complex (Figure 2, lane 10). Treatment with both ciglitazone and 9cRA resulted in a further intensification of the PPAR $\gamma$ band (Figure 2, lane 11). Additionally, there was intensification of the $\operatorname{RXR} \alpha$ supershift band (Figure 2, lane 12). We observed a faint band in the lane containing antibody to $\operatorname{RXR} \gamma$ (Figure 2, lane 14), as well as a supershift complex when using the PPAR $\gamma$ antibody (Figure 2 , lane 15). Densitometry performed on the PPAR complex bands without antibodies revealed a greater than 2.35 times increase in the formation of PPAR $\gamma$-RXR $\alpha$ heterodimer transcription factor in cells treated with both CTZ $(4.5 \mu \mathrm{M})$ and 9cRA $(10 \mu \mathrm{M})$ over that of controls. Functional heterodimer formation was 1.5 times greater in CA 9-22 cells treated with $9 \mathrm{cRA}(10 \mu \mathrm{M})$ compared to control. These data 
A

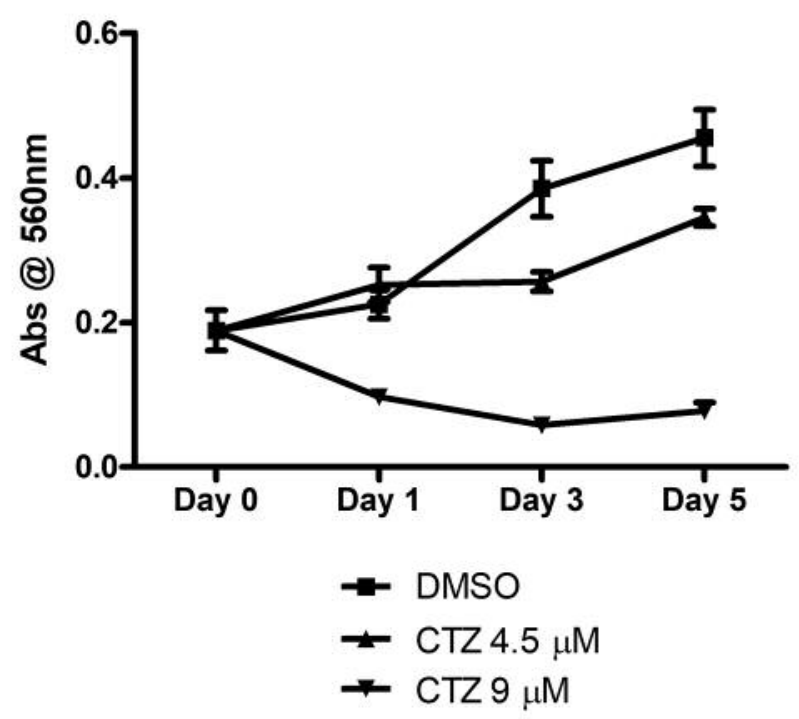

C

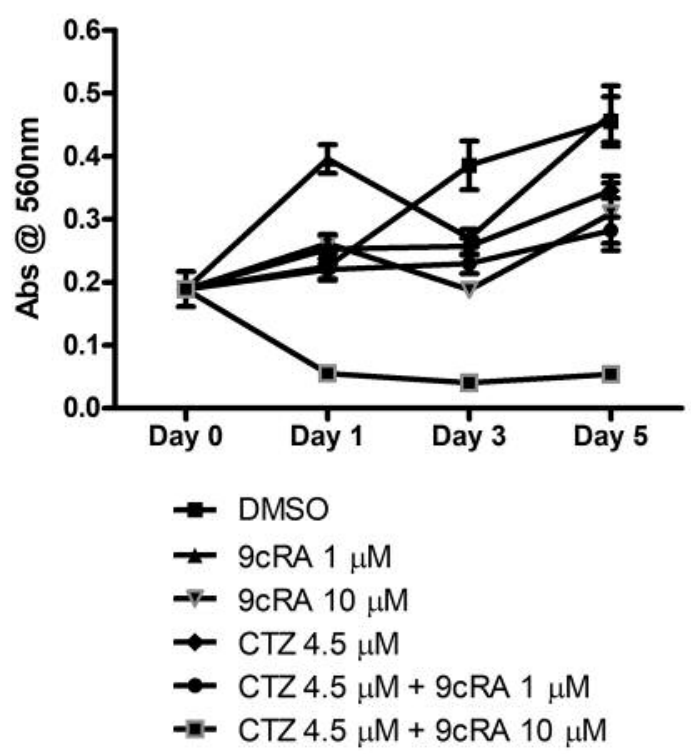

B

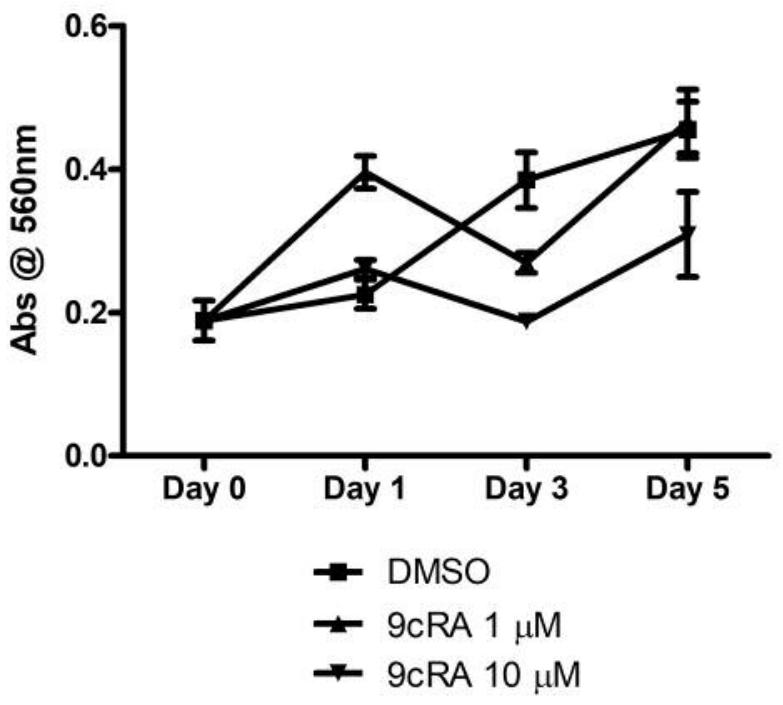

D

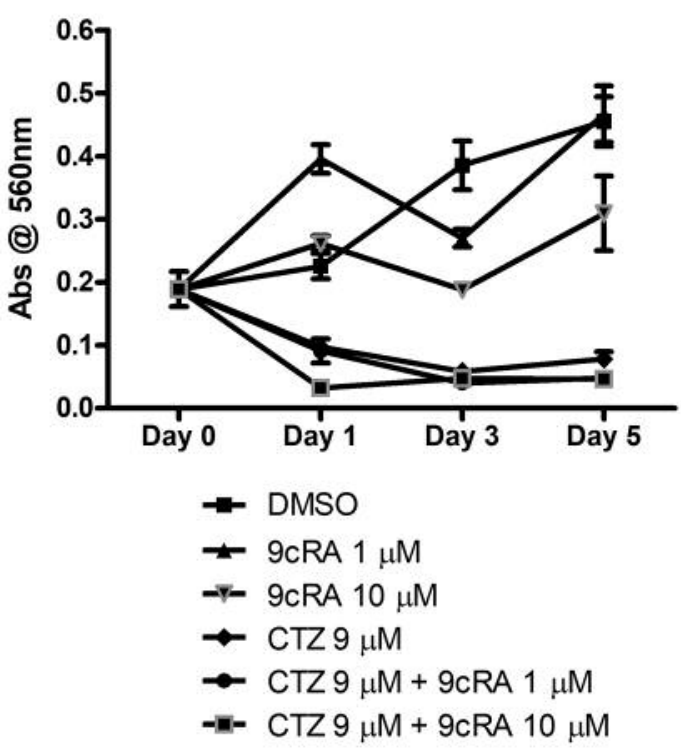

Figure 3. Cell proliferation of CA 9-22 cells. Individual $(A, B)$ treatments, as well as low-dose $(C)$ and high-dose $(D) C T Z$ combination treatments were analyzed for absorbance at $560 \mathrm{~nm}$. Each data point is the average of 6 replicates. A two-way ANOVA with Bonferroni post-test was employed during analysis. Increasing concentrations resulted in decreased proliferation during treatment with CTZ alone (panel A, $p<0.00001)$ or $9 c R A$ alone (panel $B, p<0.001$ ). Combination treatment (panels $C, D$ ) with CTZ and $9 c R A$ significantly decreased proliferation $(p<0.0001)$ compared to vehicle control. Furthermore, increasing the dosage of one therapeutic agent further attenuated proliferation $(p<0.0001)$ in comparison to low-dose combination treatment (panels $C, D$ ). This experiment was repeated multiple times with similar results.

demonstrate that both $\mathrm{CTZ}$ and 9cRA result in the formation of a nuclear PPAR $\gamma$-RXR $\alpha$ heterodimer supershift complex. The appearance of a $\operatorname{RXR} \gamma$ element after treatment is intriguing as this transcription factor protein has not been exploited for cancer prevention or treatment. In total, the
EMSA binding assays support the increased functional activity demonstrated in the luciferase experiments. These data are consistent with the reporter gene findings in Figure 1 and provide confirmation that the presumed functional heterodimer is primarily $\operatorname{PPAR} \gamma-\mathrm{RXR} \alpha$. 
A

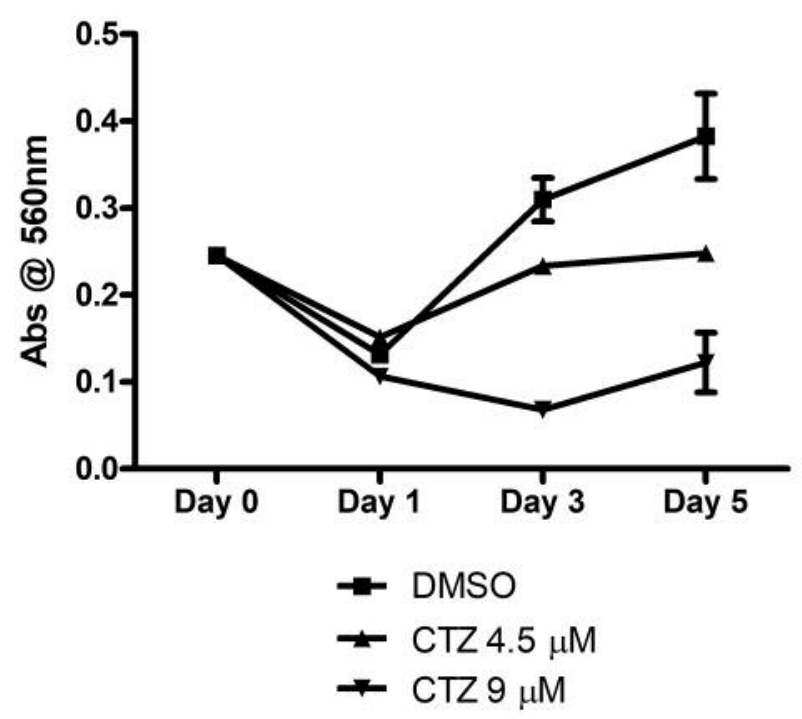

C

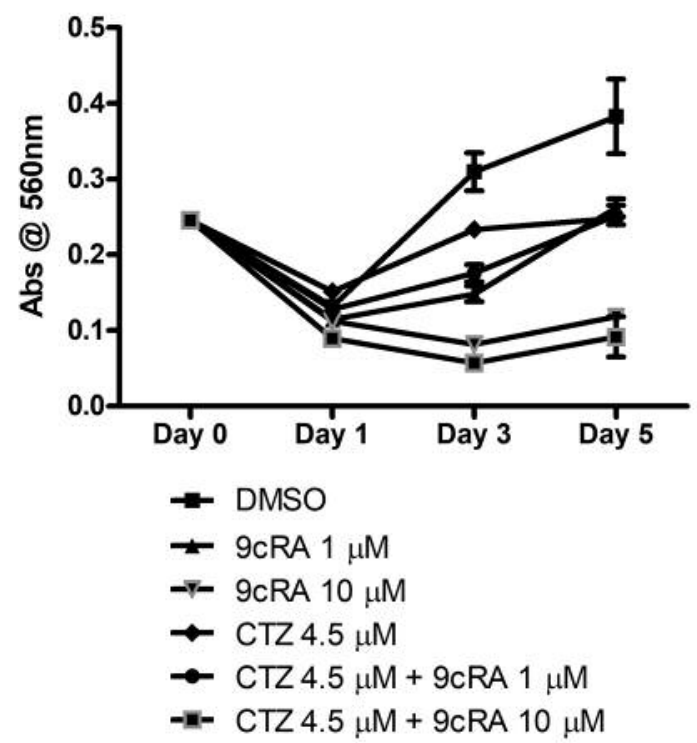

B

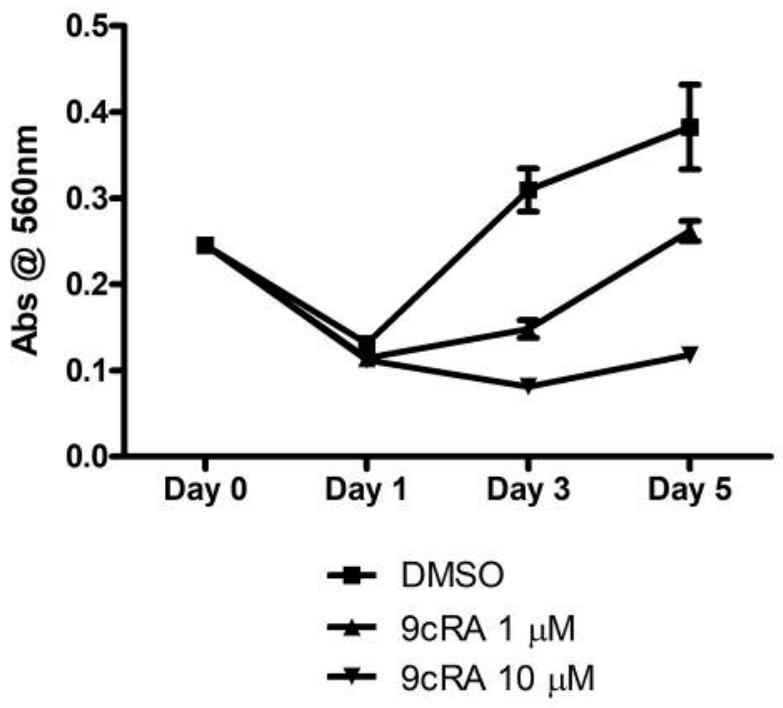

D

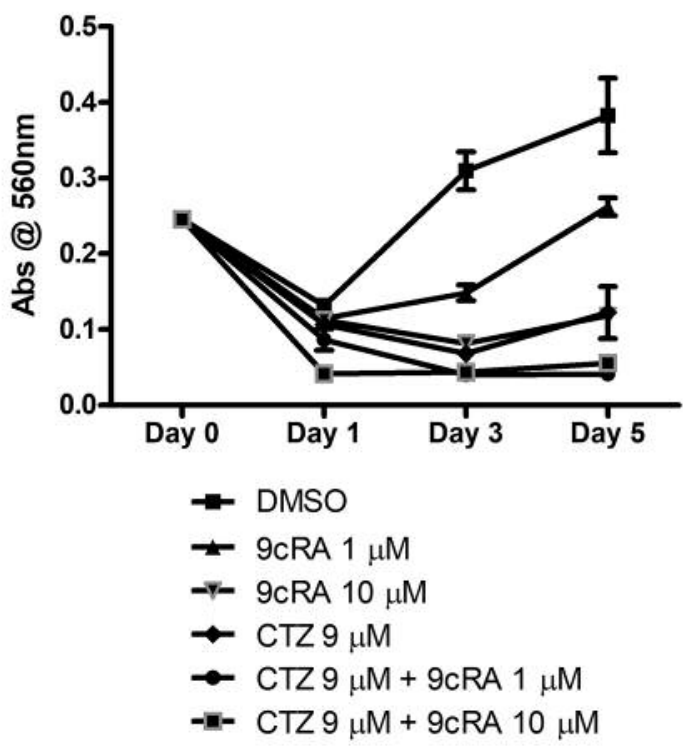

Figure 4. Cell proliferation of NA cells. Individual $(A, B)$ treatments, as well as low-dose $(C)$ and high-dose $(D) C T Z$ combination treatments were analyzed for absorbance at $560 \mathrm{~nm}$. Each data point is the average of 6 replicates. A two-way ANOVA with Bonferroni post-test was employed during analysis. Treatment with CTZ alone (panel A) or 9cRA alone (panel B) significantly decreased proliferation in comparison to control for all concentrations $(p<0.0001)$. High-dose of CTZ and $9 c R A$ further attenuated proliferation in comparison to low-dose treatments $(p<0.0001)$. Combination treatment (panels $C, D)$ significantly attenuated proliferation for all dosing combinations $(p<0.0001)$. Increasing the concentration of one therapeutic agent further decreased proliferation in comparison to low-dose combination treatments $(p<0.0001)$. This experiment was repeated multiple times with similar results.

MTT cell proliferation assay. Next, to examine a possible anti-carcinogenic effect associated with PPAR $\gamma$ activation, we analyzed cell proliferation via the MTT assay. A two-way ANOVA with a Bonferroni post-test was employed to analyze proliferation data in cell lines at day 5 after treatment with the agents, alone or in combination. In CA 922 cells, treatment with $4.5 \mu \mathrm{M} \mathrm{CTZ}$ significantly decreased proliferation in comparison to control $(t$-test: $p<0.025)$ (Figure 3A). There was a greater effect with higher doses of CTZ $(9 \mu \mathrm{M})(p<0.0001)$ and $10 \mu \mathrm{M} 9$-cRA $(p<0.01)$ with 
A

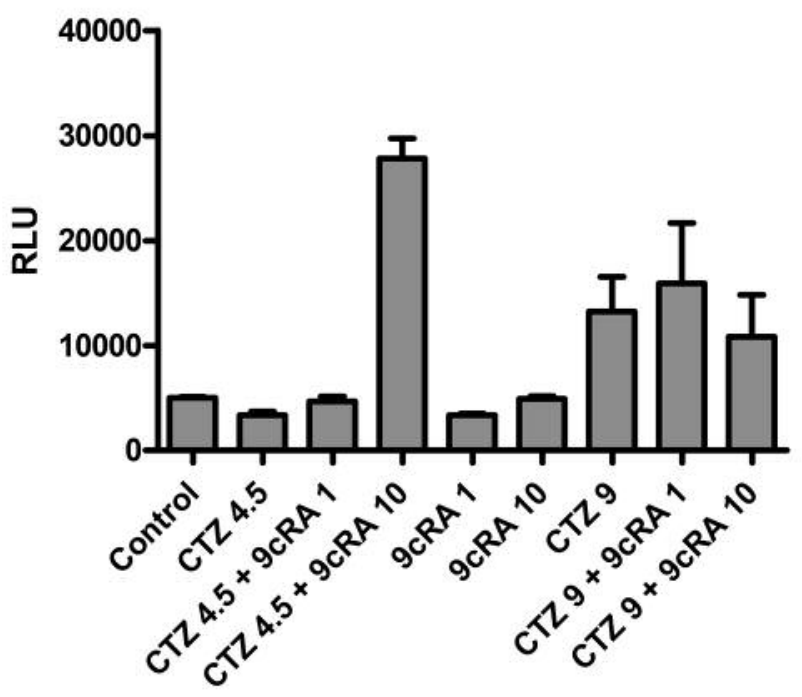

Treatment $(\mu \mathrm{M})$
B

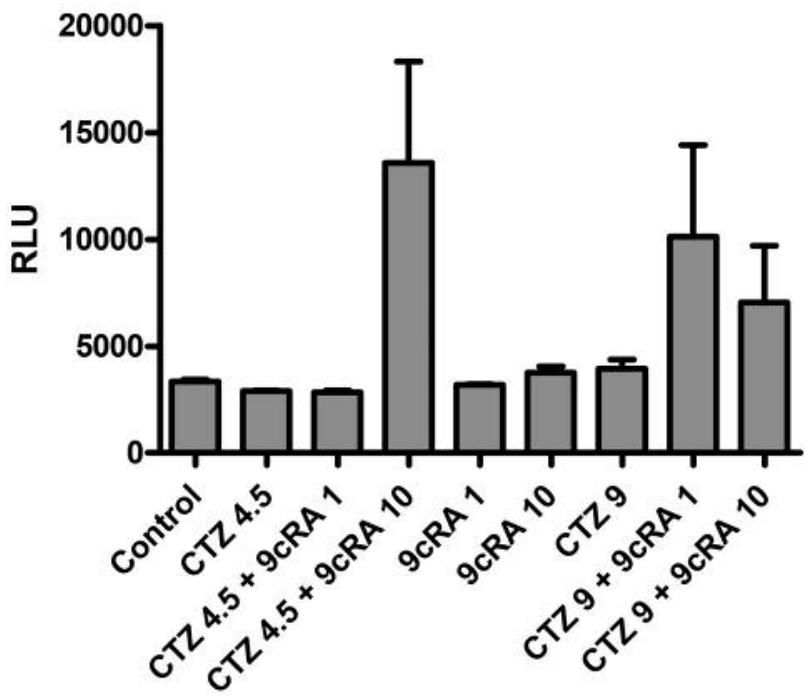

Treatment $(\mu \mathrm{M})$

Figure 5. Apoptosis was analyzed via caspase 3/7 cleavage activity in NA and CA 9-22 cells treated separately with each drug or in combination. A) CA 9-22 cells and B) NA cells. Data is the average of 3 replicates from 3 experiments. Note that combination treatments resulted in high caspase activation for the $4.5 \mu \mathrm{M}$ concentration of ciglitazone (CTZ). These experiments were repeated multiple times with similar results.

both significantly attenuating proliferation (Figure 3A, B). There was a dose-dependent decrease in proliferation of CA 9-22 cells treated independently with CTZ $(p<0.0001)$ or 9cRA $(p<0.001)$ (Figure 3A, B).

Regarding combination therapy, CTZ and 9cRA concentrations significantly decreased proliferation $(p<0.0001)$ compared to vehicle control. Proliferation was further attenuated when increasing the dosage of one therapeutic agent while holding the other at a low dose $(p<0.0001)$ in comparison to low-dose combination treatment. This was true for both CTZ and 9cRA (Figure 3C, D). There was no added benefit in increasing both concentrations in comparison with increasing the concentration of only one therapeutic agent. For example, $4.5 \mu \mathrm{M} \mathrm{CTZ}+10 \mu \mathrm{M}$ 9cRA treatment attenuated proliferation significantly more than $4.5 \mu \mathrm{M} \mathrm{CTZ}+1 \mu \mathrm{M}$ 9cRA $(p<0.0001)$, however, yielded relatively the same effect as $9 \mu \mathrm{M} \mathrm{CTZ}+10 \mu \mathrm{M} 9 \mathrm{cRA}$. However, one must also note that at 9uM CTZ that there is essentially a maximal effect of the the agent on MTT with little capacity to augment the effect further with 9cRA.

With respect to NA cell lines, all individual treatments, both low and high-dose, significantly decreased proliferation in comparison to control $(p<0.0001)$. High-dose conditions of both CTZ and 9cRA further attenuated proliferation in comparison to low-dose treatments, demonstrating a dosedependent response to both individual treatments $(p<0.0001)$ (Figure 4A, B).
Combination therapy significantly decreased proliferation for all dose concentration combinations in comparison to control $(p<0.0001)$. Similar to CA 9-22 cells, increasing the concentration of one agent further decreased proliferation in comparison to low-dose combination treatment $(p<0.0001)$. This was true for both CTZ and 9cRA. Again, there was no statistically significant added benefit in increasing the concentrations of both drugs in comparison to increasing the concentration of a single agent (Figure 4C, D). These results indicate that individual targeting of $\operatorname{RXR} \alpha$ or PPAR $\gamma$ proteins activates pathways associated with decreased cell proliferation. Combination therapy targeting both principal components of the $\operatorname{PPAR} \gamma / \operatorname{RXR} \alpha$ heterodimer further potentiated this effect.

Caspase 3/7 cleavage activity assay. We next examined apoptosis, as judged by caspase $3 / 7$ activity, in a series of substrate cleavage luciferase experiments. This was examined in both cell lines after treatment with CTZ or CTZ + 9cRA. In CA 9-22 cells we did not observe significant increases in caspase $3 / 7$ activity following treatment with $4.5 \mu \mathrm{M} \mathrm{CTZ}$ alone or with $4.5 \mu \mathrm{M} \mathrm{CTZ}+1 \mu \mathrm{M}$ 9cRA. However, treatment with $4.5 \mu \mathrm{M} \mathrm{CTZ}+10 \mu \mathrm{M} 9 \mathrm{cRA}$ resulted in a 6fold increase in caspase $3 / 7$ activation $[\mathrm{F}(3,8)=140.7$, $p<0.0001$; ANOVA). Further, treatment with $9 \mu \mathrm{M} \mathrm{CTZ}$ alone, $9 \mu \mathrm{M} \mathrm{CTZ}+1 \mu \mathrm{M}$ 9cRA, or $9 \mu \mathrm{M} \mathrm{CTZ}+10 \mu \mathrm{M}$ $9 \mathrm{cRA}$ resulted in a 2-3 fold increases in caspase 3/7 cleavage. 
However, this was not statistically significant $(p=0.067)$. Similar results were obtained using NA cells. We found that treatment with $4.5 \mu \mathrm{M} \mathrm{CTZ}+10 \mu \mathrm{M} 9 \mathrm{cRA}$ resulted in a 5 fold increase in caspase $3 / 7$ activation $[\mathrm{F}(3,8)=4.91$, $p<0.033)$. Treatment with $4.5 \mu \mathrm{M} \mathrm{CTZ}$ alone or $4.5 \mu \mathrm{M} \mathrm{CTZ}$ $+1 \mu \mathrm{M}$ 9cRA did not demonstrate significant increases. Furthermore, treatment with $9 \mu \mathrm{M} \mathrm{CTZ}, 9 \mu \mathrm{M} \mathrm{CTZ}+1 \mu \mathrm{M}$ 9cRA, or $9 \mu \mathrm{M} \mathrm{CTZ}+10 \mu \mathrm{M}$ 9cRA resulted in 2-2.5 fold increases in caspase $3 / 7$ cleavage that was not statistically significant. Over a series of several experiments, we found that addition of 1 or $10 \mu \mathrm{M} 9 \mathrm{cRA}$ to $4.5 \mu \mathrm{M} \mathrm{CTZ} \mathrm{did} \mathrm{not}$ produce significant activation of caspase $3 / 7$ (Figure 5). These effects occur at the same agent concentrations where toxicity was also observed via MTT assay (Figure 3, 4). In these experimental concentrations, these data demonstrated that CTZ + 9cRA could stimulate apoptosis in oral cancer cell lines, as judged by caspase $3 / 7$ activation.

Oil red $O$. PPAR $\gamma$ activation is associated with differentiation in adipose tissue. We were interested in examining whether this would be the case in squamous cancer cells. We assessed whether CTZ and/or 9cRA could be associated with an adipose tissue transdifferentiation response in the squamous cell lines. We evaluated the number of lipid vacuoles present in CA 9-22 cells, as judged by counting oil red $O$ positive droplets after treatment with CTZ and 9cRA. Both, treatment with $1 \mu \mathrm{M}$ 9cRA and combination of $1 \mu \mathrm{M}$ 9cRA with $9 \mu \mathrm{M}$ CTZ resulted in an average of 10 and 17-fold increase in vacuoles/cell, respectively, in comparison to the control ( $t$-test: $p<0.01, p<0.0001)$. Treatment with $9 \mu \mathrm{M} \mathrm{CTZ}$ also resulted in an average of 7-fold increase when compared to control $(t$ test: $p<0.03$ ) (Figure 6). These data suggest we can partially elicit a lineage reprogramming event to a more adipose-like phenotype by PPAR $\gamma$ activation.

\section{Discussion}

The $20-50 \%$ survival rate of stage III and IV head and neck squamous cell carcinoma has not significantly improved in the last three decades, revealing the need for innovative treatment options. Our prior research has unveiled that head and neck squamous cell carcinoma tumors had decreased expression of PPAR $\gamma$, exhibiting a paucity of the function of the heterodimer PPAR $\gamma / R X R \alpha$ transcription factor $(13,20)$. Exploiting mechanisms to enhance PPAR $\gamma$ expression and activation may reveal anti-cancer activities including decreased proliferation, increased adipocyte differentiation, and apoptosis. Furthermore, using two separate drug classes which are agonists for each principal component of the aforementioned heterodimer (retinoids and thiazolidinediones) may be a way to maximize the efficacy of this mechanism. Prior and current evidence in this manuscript reveals that an activated PPAR $\gamma$ axis is associated with multiple downstream anti-carcinogenic

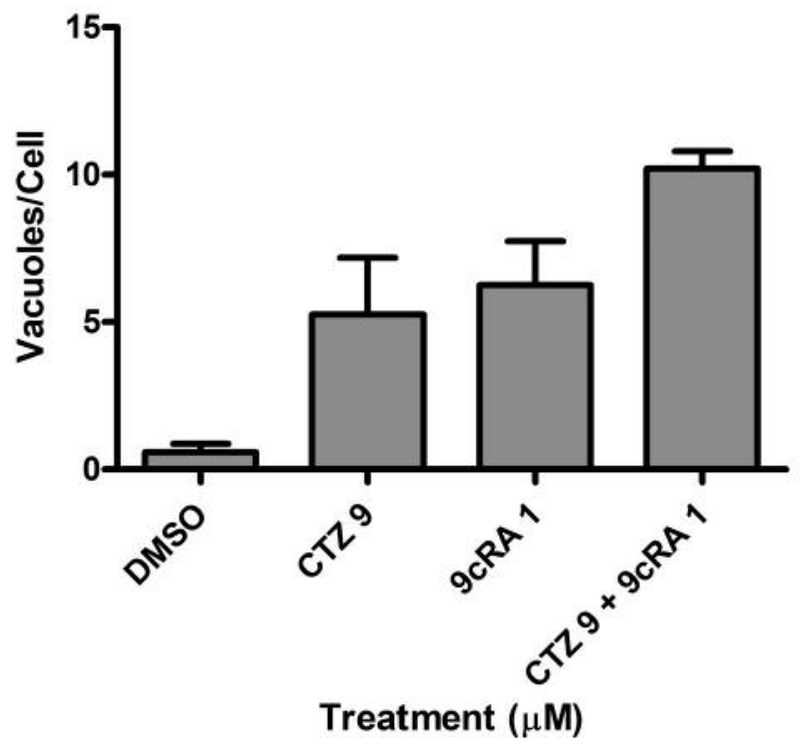

Figure 6. Oil red $O$ staining of CA 9-22 cell lines. Positive staining for intracellular lipid uptake was indicated by red deposits. Units standardized to vacuoles/cell. A Mann-Whitney U test was employed for $9 \mu M C T Z$ to correct for a non-parametric distribution due to outliers above the group mean $(p<0.03)$. One-way ANOVA analysis with Tukey post-test confirmed a statistically significant difference between all treatment conditions $[(F(3,12)=9.825, p<0.0015)]$. More Oil red $O$ was observed in treated cells than controls in several experiments with similar treatment conditions.

effects. We showed that two oral cancer cell lines treated with ciglitazone and 9-cis-retinoic acid target and activate this axis. Furthermore, functional activation of PPAR $\gamma$ was augmented when these therapeutic agents were used in combination.

Biologically relevant concentrations of 9-cis-retinoic acid and ciglitazone were able to independently up-regulate PPAR $\gamma$-DNA functional activity, as demonstrated via reporter gene analysis, by more than $300 \%$ in both NA and CA 9-22 cell lines compared to controls, with a dosedependent response regarding treatment with 9cRA concentrations. EMSA assays confirmed increased PPAR $\gamma$ activation was associated with increased PPAR $\gamma / \mathrm{RXR} \alpha$ heterodimer DNA binding in both individual and combined treatment conditions. Combination therapy demonstrated a statistically significant increased effect on PPAR $\gamma$ functional activation in both NA and CA 9-22 cell lines. Low dose 9cRA/CTZ combination treatment was able to increase PPAR $\gamma$ activation approximately two-fold when compared to independent low dose treatments. The favorable activation of the PPAR $\gamma$-RXR $\alpha$ by both agent classes indicates that titration of each drug class could be clinically exploited to maximize PPAR $\gamma$ activation, eliciting downstream anticarcinogenic effects while mitigating the toxic effects associated with each drug class. 
Cell proliferation assays consistently showed decreased cell proliferation in both cell lines when treated with a ciglitazone and/or 9-cis-retinoic acid. In both cell lines there was a dose-depended response to each agent separately (Figures 3 and 4). An additive, augmented effect was observed with the combination treatment over individual treatments. For example, when the ciglitazone concentration was held constant, a 10-fold decrease in 9-cis-retinoic acid still retained a comparable ability in reducing cancer cell proliferation. Further, this observation was supported by the apoptosis experiments (Caspase 3/7 activity, Figure 6). The highly favorable decreases in cell proliferation also supported the concept that titration of each drug class could be a highly pragmatic approach for treatment.

Analysis of oil red O staining in CA 9-22 cells corresponded with luciferase data and previous research in that both ciglitazone and 9-cis-retinoic acid induced lipid vacuole accumulation through the activation of the PPAR $\gamma$ axis. This would be an expected observation in adipose tissue, however, it is an interesting finding in squamous cancer cells. Furthermore, when therapies were combined, vacuoles/cell increased 17 -fold in comparison to baseline (Figure 6). These results provide an additional set of potential pharmacodynamic markers if thiazolidinediones and retinoids were to be used clinically in combination for head and neck squamous carcinoma therapy. Increased vacuole accumulation also correlated with decreased malignant cellular proliferation, aligning with results of previous studies indicating that increased PPAR $\gamma$ activation could result in direct differentiation of malignant cells into a non-malignant, terminal phenotype $(12,17)$.

Another observation during this project was the increased toxicity when ciglitazone was used at concentrations of $9 \mu \mathrm{M}$ or higher in combination with 9cRA. At $24 \mathrm{~h}$, there was substantial cell death. This effect was also observed at longer periods of treatment, especially at low serum concentrations. This finding was supported by our observation of actual decreases in MTT below baseline values as the incubation period increases beyond $24 \mathrm{~h}$ (data not presented here). These effects are important for clinical cancer treatment; apoptosis, cytotoxicity, and zero proliferation are important for effective cancer treatment. Further research is required to examine if these agents have other (undiscovered) intriguing effects (e.g. autophagy).

Combination treatment of tumor cell lines CA 9-22 and NA with PPAR $\gamma$ and RXR $\alpha$ agonists stimulated an increase in PPAR $\gamma$ expression in a dose-dependent fashion. Functional activation of the PPAR $\gamma$ axis resulted in downstream anticarcinogenic effects including decreased proliferation, increased apoptosis, and up-regulation of adipocyte differentiation markers. These results further substantiate existing evidence from similar cancers, which showed peroxisome proliferator-activated receptor targeting is a viable option for the treatment and/or prevention of carcinogenic growths. Furthermore, the additive/superadditive effects of the combination of these agent classes could allow minimization of toxicity while preserving the desired treatment properties. Given this, as well as the fact that the thiazolidinedione family members and 9-cis-retinoic acid are FDA approved for other clinical indications, makes them a feasible, practical combination strategy for treating head and neck squamous cell carcinoma, a disease in need for new therapies.

\section{Conflicts of Interest}

The Authors declare they have no conflicts of interest regarding this study.

\section{Authors' Contributions}

RS and FO designed the study. RS, RR, and BW carried out all experiments and drafted the manuscript. BW and FO supervised all experiments performed. SB, RR, BW, and FO participated in the data interpretation. $\mathrm{SB}, \mathrm{BW}$, and $\mathrm{FO}$ prepared the final manuscript. As the principal investigator, FO supervised the study. All Authors read and approved the final manuscript.

\section{Acknowledgements}

The Authors would like to thank Donna Seabloom for comments on the manuscript. This work was funded by the Lion's 5M Hearing Center Grant (Minnesota) and P30 CA77598-07 (NCI/NIH).

\section{References}

1 American Cancer Society. 2019 Cancer Statistics Center: Oral Cavity and Pharynx. Available at: https://cancerstatistics center.cancer.org/?_ga $=2.251606342 .1376755193 .1574128284$ $1360305065.1574128284 \#$ !/cancer-site/Oral\%20cavity\%20 and\%20pharynx [Last accessed on April 25, 2020]

2 Lippman SM, Spitz M, Trizna Z, Benner SE and Hong WK: Epidemiology, biology, and chemoprevention of aerodigestive cancer. Cancer 74: 2719-2725, 1994. PMID: 7954292.

3 Gronemeyer H, Gustafsson JA and Laudet V: Principles for modulation of the nuclear receptor superfamily. Nat Rev Drug Discov 3: 950-964, 2004. PMID: 15520817. DOI: 10.1038/ $\operatorname{nrd} 1551$

4 Almeida PE, Carneiro AB, Silva AR and Bozza PT: PPAR $\gamma$ expression and function in mycobacterial infection: roles in lipid metabolism, immunity, and bacterial killing. PPAR Res, 2012. PMID: 22851964. DOI: $10.1155 / 2012 / 383829$

5 Clark RB: The role of PPARs in inflammation and immunity. J Leukoc Biol 71: 388-400, 2002. PMID: 22851964. DOI: 10.1155/2012/383829

6 Kliewer SA, Forman BM, Blumberg B, Ong ES, Borgmeyer U, Mangelsdorf DJ, Umesono $\mathrm{K}$ and Evans RM: Differential expression and activation of a family of murine peroxisome proliferator-activated receptors. Proc Natl Acad Sci USA 91: 7355-7359, 1994. PMID: 8041794. DOI: 10.1073/pnas.91.15.7355

7 Berger J and Moller DE: The mechanisms of action of PPARs. Annu Rev Med 53: 409-435, 2002. PMID: 11818483. DOI: 10.1146/annurev.med.53.082901.104018 
8 Chang TH and Szabo E: Induction of differentiation and apoptosis by ligands of peroxisome proliferator-activated receptor gamma in non-small cell lung cancer. Cancer Res 60: 1129-1138, 2000. PMID: 10706135.

9 Bren-Mattison Y, Van Putten V, Chan D, Winn R, Geraci MW and Nemenoff RA: Peroxisome proliferator-activated receptorgamma (PPAR(gamma)) inhibits tumorigenesis by reversing the undifferentiated phenotype of metastatic non-small-cell lung cancer cells (NSCLC). Oncogene 24: 1412-1422, 2005. PMID: 15608671. DOI: 10.1038/sj.onc. 1208333

10 Warrell RP, Frankel SR, Miller WH, Scheinberg DA, Itri LM, Hittelman WN, Vyas R, Andreeff M, Tafuri A, Jakubowski A, Gabrilove J, Gordon MS and Dmitrovsky E: Differentiation therapy of acute promyelocytic leukemia with tretinoin (alltrans-retinoic acid). N Engl J Med 324: 1385-1393, 1991. PMID: 1850498. DOI: 10.1056/NEJM199105163242002

11 de Thé H, Lavau C, Marchio A, Chomienne C, Degos L and Dejean A: The PML-RAR alpha fusion mRNA generated by the $t(15 ; 17)$ translocation in acute promyelocytic leukemia encodes a functionally altered RAR. Cell 66: 675-684, 1991. PMID: 1652369. DOI: 10.1016/0092-8674(91)90113-d

12 Mangelsdorf DJ, Thummel C, Beato M, Herrlich P, Schutz G, Umesono K, Blumberg B, Kastner P, Mark M, Chambon P and Evans RM: The nuclear receptor superfamily: the second decade. Cell 83: 835-839, 1995. PMID: 1652369. DOI: 10.1016/00928674(91)90113-d

13 Ondrey F: Peroxisome proliferator-activated receptor gamma pathway targeting in carcinogenesis: implications for chemoprevention. Clin Cancer Res 15: 2-8, 2009. PMID: 19118026. DOI: 10.1158/1078-0432.CCR-08-0326

14 Sarraf P, Mueller E, Smith WM, Wright HM, Kum JB, Aaltonen LA, de la Chapelle A, Spiegelman BM and Eng C: Loss-offunction mutations in PPAR gamma associated with human colon cancer. Mol Cell 3: 799-804, 1999. PMID: 10394368. DOI: $10.1016 / \mathrm{s} 1097-2765(01) 80012-5$

15 Giaginis C, Politi E, Alexandrou P, Sfiniadakis J, Kouraklis G and Theocharis $\mathrm{S}$ : Expression of peroxisome proliferator activated receptor-gamma (PPAR- $\gamma$ ) in human non-small cell lung carcinoma: correlation with clinicopathological parameters, proliferation and apoptosis related molecules and patients' survival. Pathol Oncol Res 18: 875-883, 2012. PMID: 22426809. DOI: $10.1007 / \mathrm{s} 12253-012-9517-9$

16 Govindarajan R, Ratnasinghe L, Simmons DL, Siegel ER, Midathada MV, Kim L, Kim PJ, Owens RJ and Lang NP: Thiazolidinediones and the risk of lung, prostate, and colon cancer in patients with diabetes. J Clin Oncol 25: 1476-1481, 2007. PMID: 17442990. DOI: 10.1200/JCO.2006.07.2777

17 Demetri GD, Fletcher CD, Mueller E, Sarraf P, Naujoks R, Campbell N, Spiegelman BM and Singer S: Induction of solid tumor differentiation by the peroxisome proliferator-activated receptor-gamma ligand troglitazone in patients with liposarcoma. Proc Natl Acad Sci USA 96: 3951-3956, 1999. PMID: 10097144. DOI: 10.1073/pnas.96.7.3951
18 Burstein HJ, Demetri GD, Mueller E, Sarraf P, Spiegelman BM and Winer EP: Use of the peroxisome proliferator-activated receptor (PPAR) gamma ligand troglitazone as treatment for refractory breast cancer: a phase II study. Breast Cancer Res Treat 79: 391-397, 2003. PMID: 12846423. DOI: 10.1023/a:1024038127156

19 Smith MR, Manola J, Kaufman DS, George D, Oh WK, Mueller E, Slovin S, Spiegelman B, Small E and Kantoff PW: Rosiglitazone versus placebo for men with prostate carcinoma and a rising serum prostate-specific antigen level after radical prostatectomy and/or radiation therapy. Cancer 101: 1569-1574, 2004. PMID: 15468186. DOI: 10.1002/cncr.20493

20 Wright SK, Wuertz BR, Harris G, Abu Ghazallah R, Miller WA, Gaffney PM and Ondrey FG: Functional activation of PPAR $\gamma$ in human upper aerodigestive cancer cell lines. Mol Carcinog 56: 149-162, 2017. PMID: 26999671. DOI: 10.1002/mc.22479

21 Girnun GD, Naseri E, Vafai SB, Qu L, Szwaya JD, Bronson R, Alberta JA and Spiegelman BM: Synergy between PPARgamma ligands and platinum-based drugs in cancer. Cancer Cell 11: 395406, 2007. PMID: 17482130. DOI: 10.1016/j.ccr.2007.02.025

22 Reddy RC, Srirangam A, Reddy K, Chen J, Gangireddy S, Kalemkerian GP, Standiford TJ and Keshamouni VG: Chemotherapeutic drugs induce PPAR-gamma expression and show sequence-specific synergy with PPAR-gamma ligands in inhibition of non-small cell lung cancer. Neoplasia 10: 597-603, 2008. PMID: 18516296. DOI: 10.1593/neo.08134

23 Hong WK, Lippman SM and Wolf GT: Recent advances in head and neck cancer - larynx preservation and cancer chemoprevention: the Seventeenth Annual Richard and Hinda Rosenthal Foundation Award Lecture. Cancer Res 53: 51135120, 1993. PMID: 8221647

24 Hong WK, Endicott J, Itri LM, Doos W, Batsakis JG, Bell R, Fofonoff S, Byers R, Atkinson EN, Vaughan C, Toth BB, Kramer A, Dimery IW, Skipper P and Strong S: 13-cis-retinoic acid in the treatment of oral leukoplakia. N Engl J Med 315: 1501-1505, 1986. PMID: 3537787. DOI: 10.1056/NEJM198612113152401

25 Wadler S, Schwartz EL, Anderson P, Runowicz CD, Chuang L, Del Priore G, Hochster H, Goldberg G, Fields A, Loewen G and Haynes H: Preliminary phase II clinical and pharmacokinetic study of 9-cis retinoic acid in advanced cervical cancer. New York Gynecologic Oncology Group. Cancer J Sci Am 5: 165170, 1999. PMID: 10367173.

26 Harris G, Ghazallah RA, Nascene D, Wuertz B and Ondrey FG: PPAR activation and decreased proliferation in oral carcinoma cells with 4-HPR. Otolaryngol Head Neck Surg 133: 695-701, 2005. PMID: 16274795. DOI: 10.1016/j.otohns.2005.07.019

Received April 16, 2020

Revised April 29, 2020

Accepted April 30, 2020 